УДК 544.355-16+544.77

\title{
Исследование влияния наночастиц на давление насыщенных паров изопропилового спирта
}

\author{
И. В. Мотовой, В. П. Железный, О. Я. Хлиева \\ Одесская национальна академия пищевых технологий, ул. Канатная 112, м. Одеса, 65039, Украина
}

В настоящей работе представлены результаты экспериментального исследования давления насыщенных паров растворов наночастиц $\mathrm{Al}_{2} \mathrm{O}_{3}$ в изопропиловом спирте. Средний размер наночастиц $\mathrm{Al}_{2} \mathrm{O}_{3}$, определенный методом сканирующей электронной микроскопии составил 27,3 нм, а гидродинамический диаметр наночастии в изопропиловом спирте не превышал 50 нм. Исследования давления насыщенных паров нанофлюидов выполнены статическим методом на оригинальной экспериментальной установке в интервале температур 300 - $350 \mathrm{~K} u$ концентраций наночастиц $\mathrm{Al}_{2} \mathrm{O}_{3}$ в изопропаноле равной 2,53, 4,44, 6,87 и 9,55 масс.\%. B статье приведено описание экспериментальной установки по измерению давления насыщенных паров жидкостей. Выполненный анализ показывает, что расширенная неопределенность полученных экспериментальных данных о давлении насыщенных паров нанофлюидов не превышает 0,0006 бар (0,71\%). На основании экспериментальных данных получена информация о влиянии наночастии $\mathrm{Al}_{2} \mathrm{O}_{3}$ на давление насыщенных паров изопропанола в широком интервале температур и кониентраций наночастиц. Приведен анализ температурной и кониентрационной зависимостей давления насыщенных паров нанофлюидов изопропанол/наночастииь $\mathrm{Al}_{2} \mathrm{O}_{3}$. Показано, что присутствие наночастиц $\mathrm{Al}_{2} \mathrm{O}_{3}$ в изопропаноле способствуют увеличению давления насыщенных паров. Причем этот эффект возрастает по мере увеличения температуры и концентрации наночастиц $\mathrm{Al}_{2} \mathrm{O}_{3}$. Наибольщая разность давления насыщенного пара нанофлюида изопропанол/ наночастицы $\mathrm{Al}_{2} \mathrm{O}_{3}$ и давления насыщенного пара чистого изопропанола составляет 2,6\%. Информация, представленная в статье, имеет важное значение для разработки моделей для прогнозирования калорических свойств нанофлюидов (изобарной теплоемкости, энтальпии и энтропии) и корректного моделирования процессов теплообмена с их участием.

Ключевые слова: Эксперимент, Нанофлюид, Изопропанол, Наночастицы $\mathrm{Al}_{2} \mathrm{O}_{3}$, Давление насыщенных паров

\section{Дослідження впливу наночастинок на тиск насиченого пару ізопропілового спирту}

\author{
І. В. Мотовий, В. П. Желєзний, О. Я. Хліева
}

Одеська національна академія харчових технологій, вул. Канатна 112, м. Одеса, 65039, Україна

\begin{abstract}
У даній роботі представлені результати експериментального дослідження тиску насиченого пару розчинів наночастинок $\mathrm{Al}_{2} \mathrm{O}_{3}$ в ізопропіловому спирті. Середній розмір наночастинок $\mathrm{Al}_{2} \mathrm{O}_{3}$, визначений методом скануючої електронної мікроскопї склав 27,3 нм, а гідродинамічний діаметр наночастинок в розчині ізопропілового спирту не перевищував 50 нм. Дослідження тиску насиченого пару нанофлюідів виконано статичним методом на оригінальній експериментальній установці в інтервалі температур 300 - $350 \mathrm{~K} i$ концентрацій. наночастинок $\mathrm{Al}_{2} \mathrm{O}_{3}$ в ізопропанолі рівної 2,53, 4,44, 6,87 i 9,55 мас. \%. У статті наведено опис експериментальної установки для вимірювання тиску насиченого пару рідин. Виконаний аналіз показує, щзо розширена невизначеність отриманих експериментальних даних про тиск насиченого пару нанофлюідів не перевищує 0,0006 бар (0,71\%). На підставі експериментальних даних отримана інформація про вплив наночастинок $\mathrm{Al}_{2} \mathrm{O}_{3}$ на тиск насиченого пару изопропанола в широкому інтервалі температур $i$ концентрації наночастинок. Наведено аналіз температурної $i$ концентраційної залежностей тиску насиченого пару нанофлюїдів ізопропанол / наночастинки $\mathrm{Al}_{2} \mathrm{O}_{3}$. Показано, щуо домішки наночастинок $\mathrm{Al}_{2} \mathrm{O}_{3}$ в ізопропанолі сприяють збільшенню тиску насиченого пару. Причому цей ефект зростає зі збільшенням температури $i$ концентрації наночастинок $\mathrm{Al}_{2} \mathrm{O}_{3}$. Найбільша різниця тиску насиченого пару нанофлюіда ізопропанол / наночастинки $\mathrm{Al}_{2} \mathrm{O}_{3}$ та тиску насиченого пару чистого ізопропанола складає 2,6\%. Інформація, яка представлена в статті, має важливе значення для розробки моделей прогнозування калорічних властивостей нанофлюідів (ізобарно теплоємності, ентальпії і ентропії) $і$ коректного моделювання процесів теплообміну $з$ їх участю.
\end{abstract}

Ключові слова: Експеримент, Нанофлюід, Ізопропанол, Наночастинки $\mathrm{Al}_{2} \mathrm{O}_{3}$, Тиск насиченого пару

(C) The Author(s) 2018. This article is an open access publication

This work is licensed under the Creative Commons Attribution 4.0 International License (CC BY)

http://creativecommons.org/licenses/by/4.0/

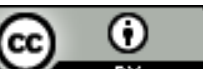




\section{1 Введение}

В последнее время внимание исследователей привлекают задачи изучения влияние наночастиц на теплофизические свойства базовых жидкостей, перспективных для использования в качестве рабочих тел парокомпрессионных холодильных машин либо в качестве хладоносителей холодильных установок. Несмотря на обилие опубликованных работ, посвященных исследованию теплофизических свойств нанофлюидов, представленные результаты требуют правильной физической интерпретации. Однако противоречивость полученных экспериментальных данных о давлении насыщенных паров, теплопроводности, вязкости, теплоемкости нанофлюидов показывает, что полученной информации еще недостаточно для того что бы приступить к задачам моделирования их термодинамических свойств.

Следует подчеркнуть, что экспериментальные данные о термических свойствах нанофлюидов несут ценную информацию о структуре нанофлюида и ее изменении в зависимости от температуры и концентрации наночастиц. Кроме того, данные о термических свойствах нанофлюидов необходимы для расчета калорических свойств (изохорной, изобарной теплоемкости, энтальпии и энтропии) технически важных нанофлюидов применяемых в холодильном оборудовании в качестве теплоносителей или рабочих тел.

Вместе с тем, следует констатировать, что публикаций, посвященных изучению влияния наночастиц на термические свойства жидкостей недостаточно. Наименее изученными остаются эффекты влияния наночастиц на давление насыщенных паров и поверхностное натяжение. Несомненно, что наличие наночастиц будет изменять структуру поверхностного слоя базовой жидкости, a, следовательно, и характер межмолекулярного взаимодействия в этом поверхностном слое. Поэтому отсутствие достоверной экспериментальной информации об эффектах влияния наночастиц на поверхностные свойства базовых жидкостей сдерживает прогресс в разработке методов моделирования термических свойств нанофлюидов.

В литературе имеется лишь несколько публикаций посвященных экспериментальному исследованию влияния наночастиц на давление насыщенных паров чистых жидкостей.

Например, в работе авторы [1] авторы приводят результаты экспериментального исследования давления насыщенных паров растворов R134a/минеральное масло/наночастицы $\mathrm{Fe}_{3} \mathrm{O}_{4}$ в интервале температур от минус 10 до $55{ }^{\circ} \mathrm{C}$ и давлений 0,2 - 1,5 МПа. На основании проведенных исследований авторы пришли к заключению, что присутсвие наночастиц $\mathrm{Fe}_{3} \mathrm{O}_{4}$ способствуют увеличению давления насыщенных паров исследованных нанофлюидов. Кроме того, авторы отмечают, что наночастицы $\mathrm{Fe}_{3} \mathrm{O}_{4}$ могут улучшить растворимость минерального масла и хладагента R134a.

В работе [2] авторы проводят результаты экспериментального исследования влияния наночастиц на давления насыщенных паров растворов хладагента R600a в компрессорном масле. Исследование влияния наночастиц $\mathrm{Al}_{2} \mathrm{O}_{3}$ на давление насыщенных паров растворов изучено при концентрации наночастиц в масле 0,50 масс.\% и массовой концентрации хладагента в растворах: 80, 65 и 39 масс.\%. Изучение влияния наночастиц $\mathrm{TiO}_{2}$ на давление насыщенных паров растворов проводилось при концентрации наночастиц 0,50 масс.\% и массовой концентрации хладагента в растворах: 87, 71 и 40 масс.\%. Проведенные исследования показывают, что добавки наночастиц в растворы хладагента R600a в компрессорном масле способствуют увеличению давления насыщенных паров растворов.

В работе [3] авторы приводят результаты исследования влияния углеродных нанотрубок и наночастиц $\mathrm{TiO}_{2}$ на давление насыщенных паров растворов R134a/ полиэффирное масло. Исследование давления насыщенных паров проведено в диапазоне следующих параметров: при двух температурах 293.15 K и $323.15 \mathrm{~K}$, в интервале концентраций хладагента в маслах от 0 до 100 \% и концентрации наночастиц в компрессорном масле 0.5 гр/литр. Полученные результаты показывают, что чистое масло и наномасло имеют одинаковую растворимости в хладагенте R134a. Это означает, что введение некоторого количества наночастиц $\left(\mathrm{TiO}_{2}\right.$ либо нанотрубок) существенно не изменяет силы взаимодействия между молекулами хладагента R134a и полиэфирным маслом. Результаты исследования давления насыщенных паров растворов в маслах и наномаслах, приведенные в работе [3], свидетельствуют о том, что термодинамические свойства смесей масла и хладагента не изменяются в присутствии наночастиц.

В работе [4] авторы приводят результаты исследования влияния наночастиц $\mathrm{Al}_{2} \mathrm{O}_{3}$ различного размера $(13,20$ и 80 нм) при их концентрациях в воде 0,01 - 2 об.\% (для каждого размера наночастиц) на давление насыщенных паров в диапазоне температур 25 - $60{ }^{\circ} \mathrm{C}$. В этой же статье приведены данные о влиянии наночастиц $\mathrm{TiO}_{2}$ (21 нм) при их концентрациях 0,012 об. \% в воде на давление насыщенных паров базовой жидкости в том же диапазоне температур. Авторами показано, что давление нанофлюида с примесями наночастиц $\mathrm{Al}_{2} \mathrm{O}_{3}$ ниже чем для чистой воды и понижается с увеличением размера наночастиц и их концентрации. Напротив при концентрации 0,01 об.\% наночастиц $\mathrm{TiO}_{2}$ в воде давление насыщенного пара при $25{ }^{\circ} \mathrm{C}$ было примерно на 7,5\% выше, чем у базового вещества.

С учетом изложенного обзора можно прийти к заключению, что результаты экспериментального изучения эффектов влияния наночастиц на давление насыщенных паров чистых жидкостей и растворов являются противоречивыми. Это обстоятельство существенно затрудняет процедуру корректного расчета калорических свойств (изобарной теплоемкости, энтальпии и энтропии) как перспективных для холодильных систем хладоносителей, так и реальных рабочих тел парокомпрессионных холодильных машин с добавками наночастиц. 


\section{2 Экспериментальная установка и методика исследования}

При изучении влияния наночастиц на давление насыщенных паров использовался нанофлюид изопропанол / $\mathrm{Al}_{2} \mathrm{O}_{3}$ с содержанием наночастиц $20 \pm 1$ масс. \% (702129 Aldrich). Основные характеристики базового нанофлюида приведены в таблице 1. Точная концентрация наночастиц в базовом нанофлюиде была определена по массе сухого остатка после испарения изопропанола из предварительно взвешенного небольшого количества базового нанофлюида. Для этой цели использовались аналитические весы A\&D GR-300 с неопределенностью $\pm 0,4$ мг.

Таблица 1 - Характеристики базового нанофлюида изопропанол / наночастицы $\mathrm{Al}_{2} \mathrm{O}_{3}$ (по данным производителя)

\begin{tabular}{|l|c|}
\hline Тест & Определение \\
\hline Внешний вид (цвет) & Белый \\
\hline Внешний вид (форма) & Суспензия \\
\hline Степень чистоты $\geq 99,9 \%$ & $\begin{array}{c}\text { Соответствует } \\
\text { требованиям }\end{array}$ \\
\hline Массовая доля наночастиц & $19,0-21,0$ масс. $\%$ \\
\hline рН нанофлюида & $7,5-9,5$ \\
\hline $\begin{array}{l}\text { Размер наночастиц } \\
\text { (определенный методом } \\
\text { динамического рассеяния света) }\end{array}$ & $\leq 50$ нм \\
\hline
\end{tabular}

Образцы для исследования давления насыщенных паров были приготовлены путем разбавления базового нанофлюида (702129 Aldrich) изопропиловым спиртом (CAS 67-63-0, чистота 99,7\%). Образцы нанофлюида гомогенизировались простым кратковременным механическим встряхиванием. Точная концентрация наночастиц в полученных образцах была определена гравиметрическим методом с использованием аналитических весов. Полученные образцы являлись стабильными во времени коллоидными растворами в широком диапазоне концентраций наночастиц и температур. Коллоидная стабильность образцов этого нанофлюида была подробно изучена в работе [5].

Приготовленные для исследования давления насыщенных паров образцы имели следующие концентрации наночастиц $\mathrm{Al}_{2} \mathrm{O}_{3}: 2,53,4,44,6,87$ и 9,55 масс. \%.

Дополнительно был исследован средний размер наночастиц $\mathrm{Al}_{2} \mathrm{O}_{3}$ в образце после испарения из него базовой жидкости. С этой целью использовался метод электронной сканирующей микроскопии. Изображение наночастиц полеченное данным методом приведено на рис. 1. Гистограмма распределения наночастиц по размерам приведена на рис. 2. Средний размер (средний эквивалентный диаметр) наночастиц в сухом образце составил 27.3 нм.

Массовую долю наночастиц в образцах нанофлюидов определяли по следующему уравнению:

$$
w_{N P}=\frac{m_{N F} \cdot w_{N F}}{m_{N F}+m_{B F}-m_{B F}^{\prime \prime}}
$$

где $m_{N F}$-масса нанофлюида, г; $w_{N F}$ - массовая доля наночастиц в базовом (концентрированном) нанофлюиде, $г \Gamma^{-1} ; m_{B F}$ - масса базовой жидкости (изопропанола), г; $m_{B F}^{\prime \prime}$ - масса паровой фазы базовой жидкости, г.

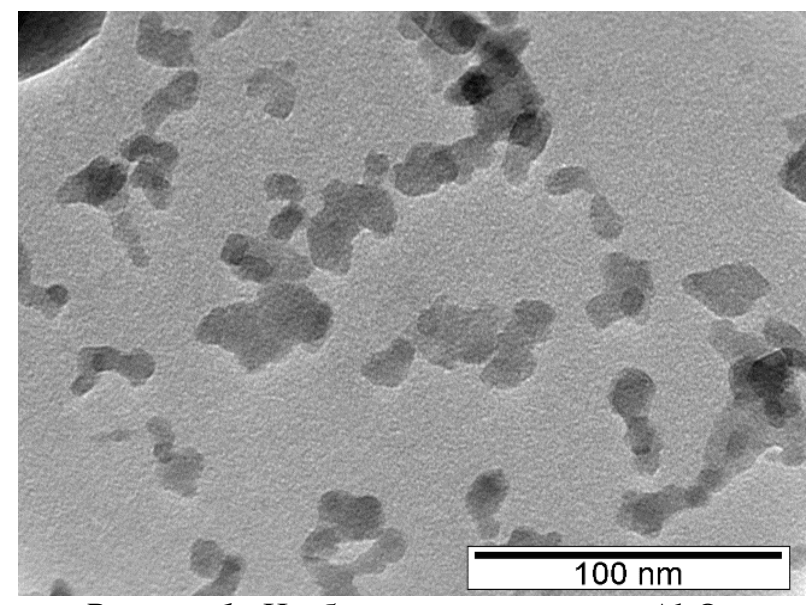

Рисунок 1 - Изображение наночастиц $\mathrm{Al}_{2} \mathrm{O}_{3}$, полученное методом электронной сканирующей микроскопии

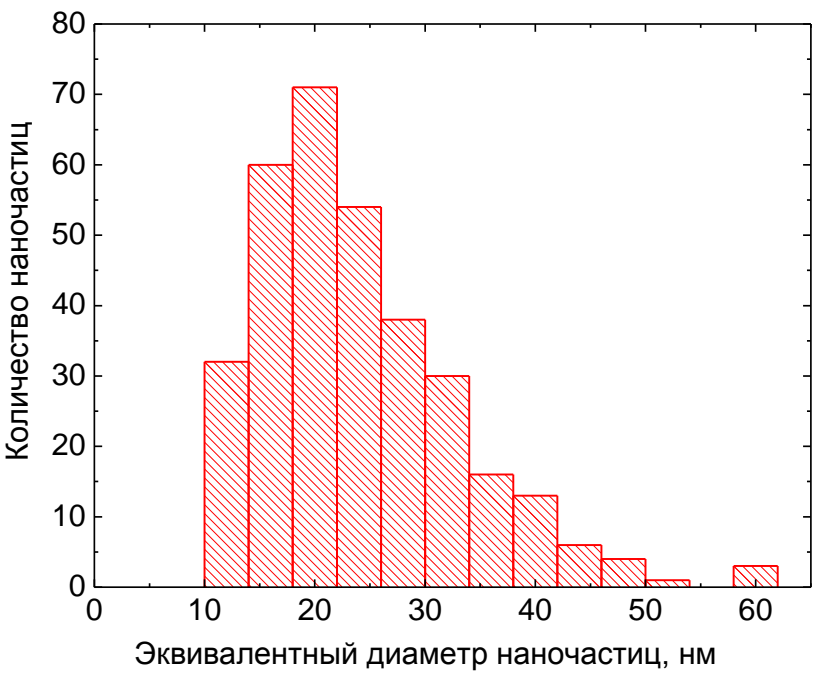

Рисунок 2 - Распределение наночастиц $\mathrm{Al}_{2} \mathrm{O}_{3}$ по размерам

Давление насыщенных паров измерено статическим методом на установке, схема которой представлена на рисунке 3. Измерительная ячейка 1 (пьезометр постоянного объема) располагалась в термостате 16. Термостат оснащен системой автоматического регулирования температуры 6. Колебания температуры в термостате не превышали 0,02 К. Измерение давления осуществлялось при помощи пьезоэлектрического преобразователя давления 10 WIKA S-10, который соединялся с измерительной ячейкой «балластным» капилляром. Преобразователь давления был оснащен стабилизированным источником питания 8. Выходной сигнал преобразователя давления - сила тока (от 4 до 20 мА) - измерялся мультиметром 11. Границы отклонения значений тока от его оценки в диапазоне до 20 мА при использовании мультиметра RIGOL DM3064 не превышали 0,016 \%. Во избежание конденсации паров исследуемого вещества в «балластном» капилляре, его 
перегревали относительно температуры в термостате с помощью нагревателя 12, подключенного к источнику питания 7. Контроль за температурой «балластного» капилляра осуществляется термопарой подключенной к мультиметру 11.

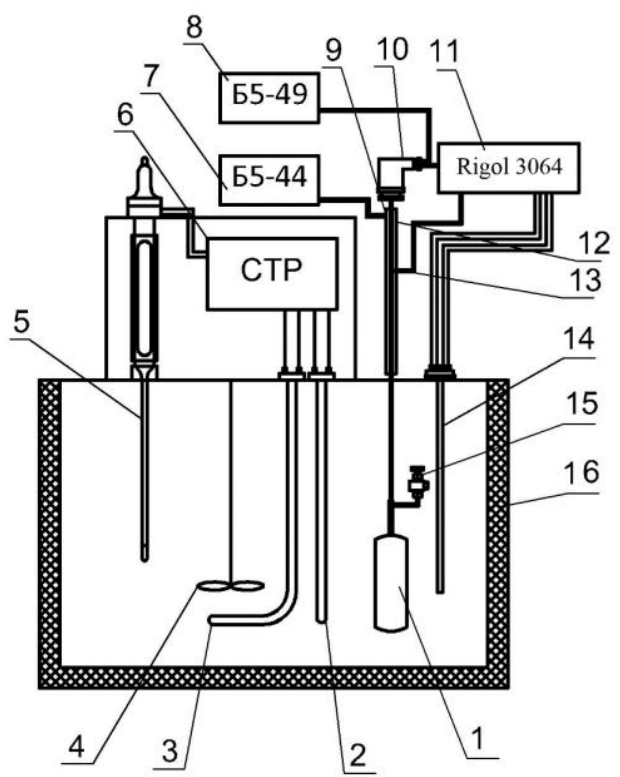

Рисунок 3 - Схема экспериментальной установки для исследования давления насыщенных паров чистых веществ и растворов: 1 - измерительная ячейка; 2 фоновый нагреватель; 3 - разгонный нагреватель; 4 мешалка; 5 - контактный термометр, 6 - система терморегулирования; 7 - источник постоянного питания Б5-44; 8 - источник постоянного питания Б5-49; 9 нагреватель; 10 - датчик давления WIKA S-10; 11 мультиметр Rigol 3064; 12 - нагреватель; 13 термопара; 14- платиновый термометр сопротивления TR10-A; 15 -вентиль;16 - термостат

В опытах использовался преобразователь давления с диапазоном измеряемых давлений - (-1 - 0) бар. Границы отклонений от оценки измеряемых давлений не превышают 0,25\% от максимального значения в указанных диапазонах измерений преобразователя.

Измерение температуры осуществляется платиновым термометром сопротивления 14 марки TR10-A. Границы отклонений от оценки измеренных значений температуры не превышали 0,15 и 0,35 К при температурах 0 и $100^{0} \mathrm{C}$ соответственно. Термометр подключается к мультиметру 11 по четырехпроводной схеме. Границы отклонений от оценки измеренных значений сопротивления в диапазоне до 200 Ом для мультиметра RIGOL DM3064 не превышали 0.022 \%. Термометр устанавливался вблизи средней части измерительной ячейки 1.

\section{3 Результаты экспериментального исследования}

Полученные экспериментальные данные о давлении насыщенных паров нанофлюидов изопропанол/ наночастицы $\mathrm{Al}_{2} \mathrm{O}_{3}$ приведены в таблице 2 .
Таблица 2 - Экспериментальные данные по давлению насыщенных паров нанофлюида изопропанол/наночастицы $\mathrm{Al}_{2} \mathrm{O}_{3}$.

\begin{tabular}{|c|c|c|c|c|c|}
\hline$T, \mathrm{~K}$ & $P$, бар & $T, \mathrm{~K}$ & $P$, бар & $T, \mathrm{~K}$ & $P$, бар \\
\hline \multicolumn{7}{|c|}{ Изопропанол (ИПС) } \\
\hline 297,8 & 0,0578 & 315,8 & 0,1622 & 344,7 & 0,6392 \\
\hline 303,1 & 0,0800 & 332,1 & 0,36062 & \\
\hline \multicolumn{7}{|c|}{ ИПС $+\mathrm{Al}_{2} \mathrm{O}_{3} 2,53$ масс \% } \\
\hline 303,6 & 0,0832 & 325,9 & 0,2735 & 342,4 & 0,5924 \\
\hline \multicolumn{7}{|c|}{ ИПС $+\mathrm{Al}_{2} \mathrm{O}_{3} 4,44$ масс, \% } \\
\hline 303,2 & 0,0837 & 323,5 & 0,2487 & 340,4 & 0,5502 \\
\hline \multicolumn{7}{|c|}{ ИПС $+\mathrm{Al}_{2} \mathrm{O}_{3} 6,87$ масс \% } \\
\hline 303,8 & 0,0894 & 316,0 & 0,1700 & 352,6 & 0,92730 \\
\hline 305,7 & 0,0994 & 332,3 & 0,38153 \\
\hline \multicolumn{7}{|c|}{ ИПС $+\mathrm{Al}_{2} \mathrm{O}_{3} 9,55$ масс \% } \\
\hline 304,1 & 0,0902 & 315,3 & 0,1636 & 334,1 & 0,4138 \\
\hline 314,5 & 0,1579 & 333,7 & 0,4098 & 351,4 & 0,8848 \\
\hline
\end{tabular}

Экспериментальные данные по давлению насыщенных паров в исследованном диапазоне температур были описаны уравнением (2). Это уравнение обладает хорошими экстраполяционными возможностями при расчете давления насыщенных паров исследуемых образцов в области низких температур.

$$
\ln \left(P_{S}\right)=A(x)+B(x) \frac{1}{T},
$$

где $P_{S}$ - давление насыщенных паров, бар; $T$ температура, К; $A(x), B(x)$ - коэффициенты значение которых зависит от концентрации наночастиц в изопропаноле.

Концентрационные зависимости коэффициентов $A(x), B(x)$ были аппроксимированы уравнениями:

$$
\begin{gathered}
A(x)=-5237,7+802,79 \cdot w_{N P}, \\
B(x)=14,762-2,027 \cdot w_{N P},
\end{gathered}
$$

где $w_{N P}-$ массовая доля наночастиц, г $\Gamma^{-1}$.

Температурная и концентрационная зависимости давления и разности давлений насыщенных паров нанофлюидов изопропанол/ наночастицы $\mathrm{Al}_{2} \mathrm{O}_{3}$ приведены на рисунках 4 -6.

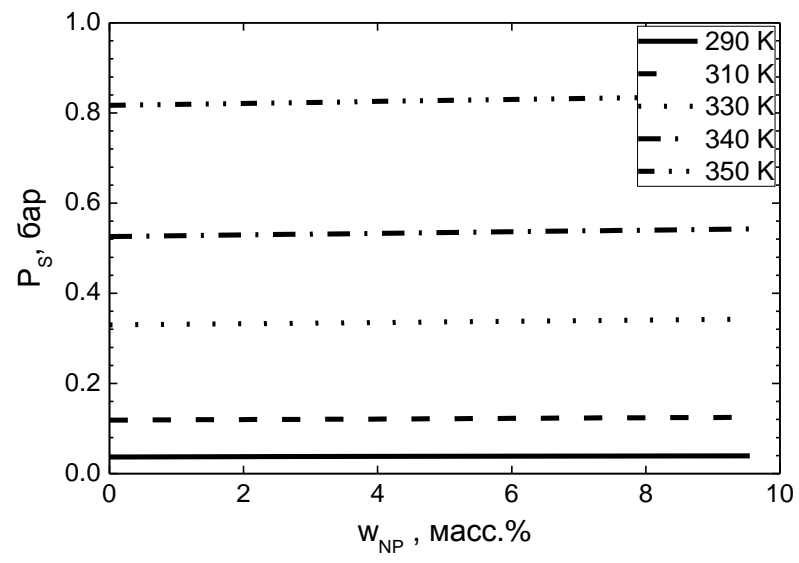

Рисунок 4 - Концентрационная зависимость давления насыщенных паров нанофлюида изопропанол/ $\mathrm{Al}_{2} \mathrm{O}_{3} P_{S}$ при нескольких значениях температур 


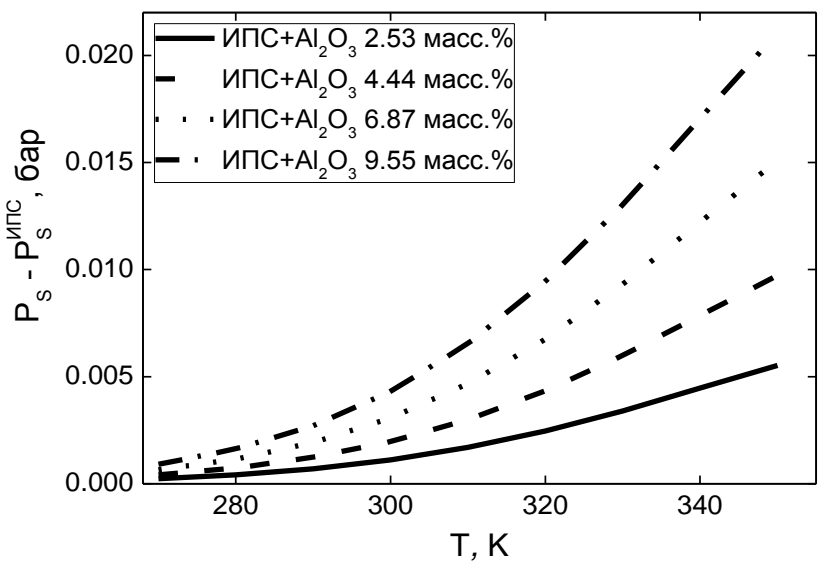

Рисунок 5 - Температурная зависимость абсолютной разницы давлений насыщенного пара нанофлюида изопропанол $/ \mathrm{Al}_{2} \mathrm{O}_{3} P_{S}$ от давлений насыщенного пара чистого изопропанола $P_{S}{ }^{\text {ИПС }}$, рассчитанных по уравнению (2)

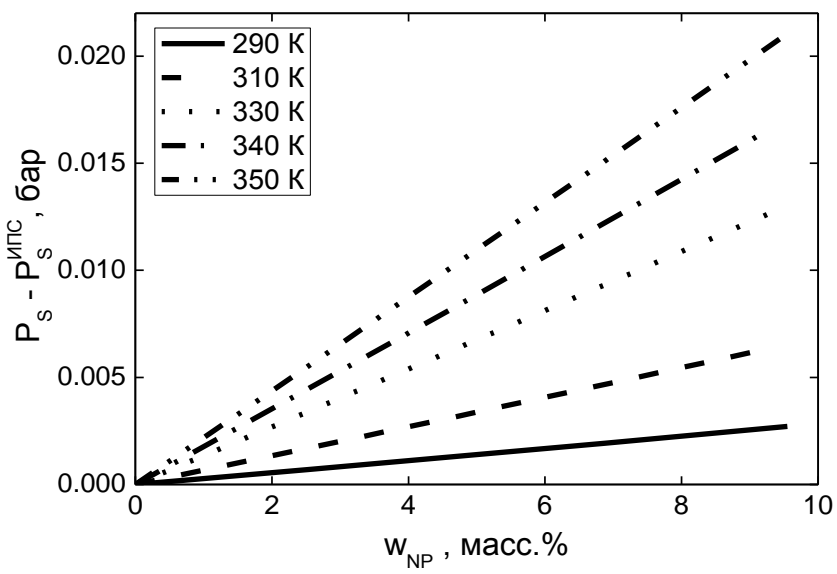

Рисунок 6 - Концентрационная зависимость абсолютной разницы давлений насыщенного пара нанофлюида изопропанол/ $\mathrm{Al}_{2} \mathrm{O}_{3} P_{S}$ от давлений насыщенного пара чистого изопропанола $P_{S}{ }^{\text {иПС }}$, рассчитанных по уравнению (2)

Отклонения экспериментальных данных о давлении насыщенных паров нанофлюидов изопропанол/ $\mathrm{Al}_{2} \mathrm{O}_{3}$ от рассчитанных по уравнениям (2)-(4) представлены на рисунке 7 .

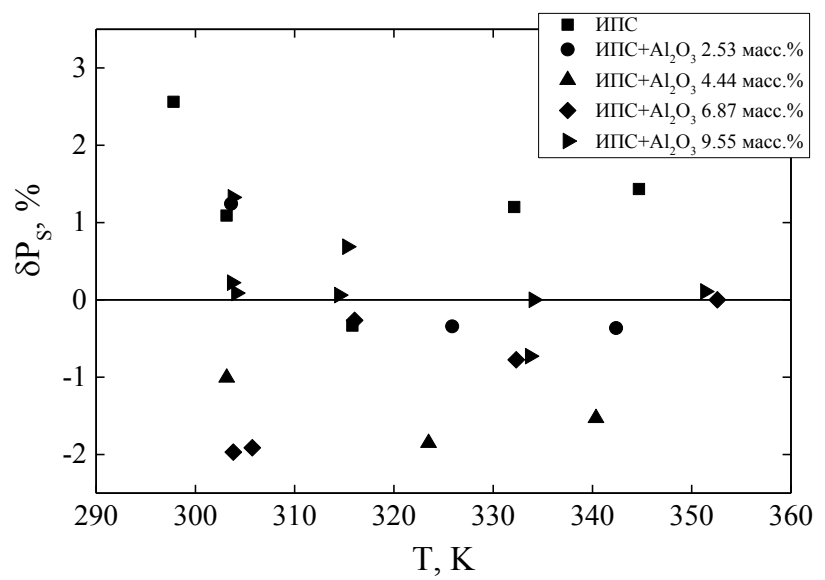

Рисунок 7 - Температурная зависимость относительных отклонений экспериментальных данных по давлению насыщенных паров нанофлюидов изопропанол/ $\mathrm{Al}_{2} \mathrm{O}_{3}$ от значений, рассчитанных по уравнениям (2)-(4)

Выполненный анализ показывает, что расширенная неопределенность полученных экспериментальных данных о давлении насыщенных паров нанофлюидов не превышает 0,0006 Па $(0,71 \%)$.

Из приведенной на рисунках 4- 7 информации следует, что эффект влияния наночастиц $\mathrm{Al}_{2} \mathrm{O}_{3}$ на давление насыщенных паров проявляется более заметно при высоких температурах (см. рисунок 4). С увеличением температуры и концентрации наночастиц $\mathrm{Al}_{2} \mathrm{O}_{3}$ абсолютная разница давлений насыщенного пара нанофлюида изопропанол/ $\mathrm{Al}_{2} \mathrm{O}_{3}$ от давления насыщенного пара чистого изопропанола увеличивается (см. рисунки 5 и 6). Из полученных данных следует, что силы межмолекулярного взаимодействия в поверхностном слое жидкой фазы изопропанола уменьшаются в присутствии наночастиц, что способствует увеличению давления насыщенных паров изопропанола. Наибольшая разность давления насыщенного пара нанофлюида изопропанол/ $\mathrm{Al}_{2} \mathrm{O}_{3}$ от давления чистого изопропанола наблюдается при концентрации наночастиц 9,55 масс. \% и температуре 350 К и составляет $2,6 \%$.

\section{4 Выводы}

В результате проведенного исследования впервые получена информация о влиянии наночастиц $\mathrm{Al}_{2} \mathrm{O}_{3}$ на давление насыщенных паров изопропанола в широком интервале температур и концентрации наночастиц. Полученная экспериментальная информация о давлении насыщенных паров для модельной термодинамической системы изопропанол/ наночастицы $\mathrm{Al}_{2} \mathrm{O}_{3}$ позволяет прийти к выводу о том, что примеси наночастиц в изопропаноле способствуют увеличению давления насыщенных паров. Причем этот эффект увеличивается по мере увеличения температуры и концентрации наночастиц $\mathrm{Al}_{2} \mathrm{O}_{3}$. Наибольшая разность давлений насыщенного пара нанофлюида изопропанол/ $\mathrm{Al}_{2} \mathrm{O}_{3}$ от давления насыщенного пара чистого изопропанола достигает $2,6 \%$. Поэтому этот значительный по величине эффект необходимо учитывать при расчете калорических свойств (изобарной теплоемкости, энтальпии и энтропии) рабочих тел парокомпрессионных холодильных установок при оценке перспективности применения нанотехнологий в холодильном оборудовании [6].

\section{Литература}

1. $\mathrm{Xu} \mathrm{R}$. et al. Affection of nano-Fe3O4 on the saturated pressure of mixture HFC134a / mineral oil // International Congress of Refrigeration. 2007. Vol. 1. P. 2-5.

2. Zhelezny V.P. et al. A complex investigation of the nanofluids R600a-mineral oil-AL2O3 and R600a-mineral oil-TiO2 . Thermophysical properties // International Journal of Refrigeration. 2017. Vol. 74. P. 488-504. doi: 10.1016/j.ijrefrig.2016.11.008.

3. Bobbo S. et al. Influence of nanoparticles dispersion in POE oils on lubricity and R134a solubility // International 
Journal of Refrigeration. 2010. Vol. 33. No 6. P. 1180 1186. doi: 10.1016/j.ijrefrig.2010.04.009.

4. Tso C.Y., Chao C.Y.H. Study of enthalpy of evaporation, saturated vapor pressure and evaporation rate of aqueous nanofluids // International Journal of Heat and Mass Transfer. 2015. Vol. 84. P. 931-941. doi: 10.1016/j.ijheatmasstransfer.2015.01.090.

5. Zhelezny V. et al. Effect of Al2O3 Nanoparticles Additives on the Density, Saturated Vapor Pressure,
Surface Tension and Viscosity of Isopropyl Alcohol // International Journal of Thermophysics. 2018. doi: 10.1007/s10765-018-2361-8.

6. Zhelezny V. et al. Caloric properties of R600a solutions in compressor oil containing fullerenes C60 // Proc. the 13th IIR Gustav Lorentzen Conference on Natural Refrigerants. Valencia, Spain. June 18 to 20, 2018. DOI: 10.18462/iir.gl.2018.1176.

\title{
Investigation of the effect of nanoparticles on isopropyl alcohol saturated vapor pressure
}

\author{
I.V. Motovoy, V.P. Zhelezny, O. Ya. Khliyeva \\ Одеська національна академія харчових технологій, вул. Канатна 112, м. Одеса, 65039, Україна
}

\begin{abstract}
This paper presents the results of the experimental study of the saturated vapor pressure of isopropyl alcohol / Al2O3 nanoparticles solutions. The average size of the Al2O3 nanoparticles determined by the scanning electron microscope method was $27.3 \mathrm{~nm}$ and the hydrodynamic diameter of the nanoparticles in isopropyl alcohol did not exceed $50 \mathrm{~nm}$. The saturated vapor pressure was investigated by a static method using an original experimental setup in the temperature range 300 - $350 \mathrm{~K}$ and concentrations 2.53, 4.44, 6.87 and 9.55 wt.\%. of Al2O3 nanoparticles in isopropyl alcohol. The description of the experimental setup for measuring the saturated vapor pressure of liquids is given. The performed analysis shows that the expanded uncertainty of the obtained experimental data on the saturated vapor pressure of nanofluids does not exceed 0.0006 bar $(0.71 \%)$. Based on the experimental data we have obtained the information on the effect of Al2O3 nanoparticles additives on the saturated vapor pressure of isopropyl alcohol in a wide range of temperatures and nanoparticle concentrations. The analysis of the temperature and concentration dependences of the saturated vapor pressure of isopropyl alcohol / Al2O3 nanoparticles is given. It is shown that the additives of Al2O3 nanoparticles in isopropyl alcohol contribute to the increase in the saturated vapor pressure. Moreover, this effect increases with increasing temperature and concentration of Al2O3 nanoparticles. The greatest difference in the saturated vapor pressure of isopropyl alcohol / Al2O3 nanoparticle from that of pure isopropanol reaches $2.6 \%$. The information presented in the paper is important for the development of models for predicting the caloric properties (isobaric heat capacity, enthalpy, and entropy) of nanofluids and for correct modeling of heat exchange processes.
\end{abstract}

Keywords: Experiment, Nanofluid, Isopropanol, $\mathrm{Al}_{2} \mathrm{O}_{3}$, Nanoparticles, Saturated Vapor Pressure

\section{References}

1. $\mathrm{Xu} \mathrm{R}$. et al. Affection of nano-Fe3O4 on the saturated pressure of mixture HFC134a / mineral oil // International Congress of Refrigeration. 2007. Vol. 1. P. 2-5.

2. Zhelezny V.P. et al. A complex investigation of the nanofluids R600a-mineral oil-AL2O3 and R600a-mineral oil-TiO2 . Thermophysical properties // International Journal of Refrigeration. 2017. Vol. 74. P. 488-504. doi: 10.1016/j.ijrefrig.2016.11.008.

3. Bobbo S. et al. Influence of nanoparticles dispersion in POE oils on lubricity and R134a solubility // International Journal of Refrigeration. 2010. Vol. 33. No 6. P. 1180 1186. doi: 10.1016/j.ijrefrig.2010.04.009.

4. Tso C.Y., Chao C.Y.H. Study of enthalpy of evaporation, saturated vapor pressure and evaporation rate of aqueous nanofluids // International Journal of Heat and Mass
Transfer. 2015. Vol. 84. P. 931-941. doi: 10.1016/j.ijheatmasstransfer.2015.01.090.

5. Zhelezny V. et al. Effect of $\mathrm{Al} 2 \mathrm{O} 3$ Nanoparticles Additives on the Density, Saturated Vapor Pressure, Surface Tension and Viscosity of Isopropyl Alcohol // International Journal of Thermophysics. 2018. doi: 10.1007/s10765-018-2361-8.

6. Zhelezny V. et al. Caloric properties of R600a solutions in compressor oil containing fullerenes C60 // Proc. the 13th IIR Gustav Lorentzen Conference on Natural Refrigerants. Valencia, Spain. June 18 to 20, 2018. DOI: 10.18462/iir.gl.2018.1176. 